\title{
The socio-economic effects of mechanising and/or modernising hard rock mines in South Africa
}

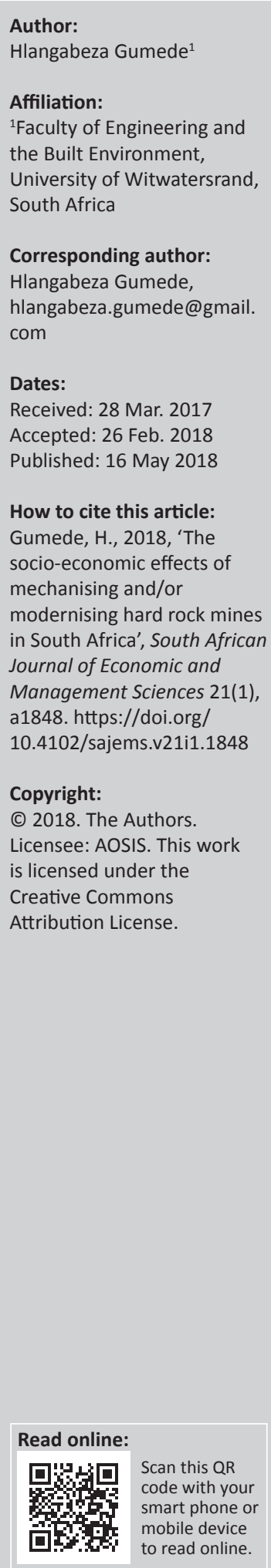

Background and aim: This article aims to explore stakeholders' views on the potential effects of modernising hard rock mines in South Africa.

Methods: This objective was achieved through eliciting and bringing together the views of different stakeholders. Different stakeholders were interviewed using qualitative research methodologies. The sample demographics were fairly representative and ranged from operators to executives and from employee to employer representatives. The main form of data collection was one-on-one face-to-face interviews.

Results: One of the major findings of this research is that stakeholders have different levels of understanding of mechanisation and modernisation. The levels of understanding were found to be proportional to the levels of education.

Conclusion: There seems to be general support for mechanisation and modernisation among the participants. The identified socio-economic challenges and benefits were relatively similar and aligned among participants. The main difference, however, pertained to the depth and scope of the problem or opportunity as perceived by different participants. Interviewees were also unanimous in identifying the social-economic benefits of mechanisation; these were in line with those identified in the literature, namely benefits in occupational health and safety issues, efficiency, costs and improved life of mines. Furthermore, participants viewed mechanisation and modernisation as an opportunity to reskill themselves and to improve operations and quality of life. More importantly, stakeholders seemed to share a common vision and interest of the future; as such, they were able to see beyond their constituencies and interests.

\section{Background and context}

The mining industry is an important contributor to the current and future economy of the Republic of South Africa (RSA). The estimated economic value of the mineral reserves in the country is about $\$ 2.5$ trillion (Mining Weekly 2016). The country has about $90 \%$ of known platinum group metals (PGMs) reserves in the world and has supplied over $10 \%$ of all the gold in the world (Department of Minerals and Energy 2009). The mining industry directly contributes about $8 \%$ of the country's gross domestic product (GDP) and this contribution can be as high as $17 \%$ if indirect and induced effects are added. The gold and PGM mining companies (hard rock mines) contribute about $30 \%$ of the total mining contribution to the GDP. Furthermore, the industry directly employs about 462000 people (Chamber of Mines 2014), and an additional 800000 people are employed indirectly by the industry, namely mining-dependent subsector industries (Chamber of Mines 2014). A study in 2008 estimated that every mine worker employed in the mines has 10 other people who are financially dependent on their employment (Chamber of Mines 2009). All these facts indicate that the mining industry plays a significant role in both the economic status and socio-economic status of the country. However, there is a general perception that the current conventional method of hard rock mining in RSA is unsustainable. The current conventional mining methodology is deemed unsustainable due to rising labour costs, weak metal prices, occupational health and safety concerns and low productivity levels.

Modernisation of mines in the form of mechanisation has the potential to improve the competitiveness, health and safety and profitability issues within the mining industry in RSA. Most mining companies in RSA are already implementing their mechanisation plans and most mines will be mechanised in the next decade. The improvements that come with mechanisation will have varying impacts on different stakeholders. On a short-term basis, mechanisation 
generally has a negative effect on the labour complement and on the communities in which these mining companies operate (Hattingh, Sheer \& Du Plessis 2010). However, the net effect of not mechanising can also be worse on a mediumto long-term basis. It is therefore important to explore how different stakeholders are impacted by such an initiative and to explore the views of stakeholders regarding the potential effects of modernising RSA's hard rock mines. Identifying and analysing stakeholders' concerns and mitigating the negative effects of mechanisation (modernisation) may potentially lead to a win-win scenario for all stakeholders. For instance, critical stakeholders such as labour unions traditionally oppose the mechanising of mines; however, Kaupp, Makarenko \& Durrant-Whyte (2010) have shown that mechanisation may not necessarily lead to job losses but to different employment demographics such as the employment of more skilled people and to the upskilling of the current workforce.

\section{Introduction to mine mechanisation in the South African context}

In simple terms, mechanisation involves the substitution of manual tasks carried out by people or animals with machinery. The machinery becomes the interface between the humans and the task. Automation is the next phase of mechanisation, where the interaction between humans and tasks is further reduced through modern information and control systems. In the South African gold and PGM mines, such classification is ingrained within the mining methods classification and characteristics. For instance, it is generally accepted that conventional hard rock mining is manual (Egerton 2004; Musingwini \& Minnitt 2008; Nong 2010). However, conventional mining uses handheld drilling machines for the drilling task while scraper winches and mechanical loaders are used for the subsequent cleaning task. Mechanised mining methods are normally carried out in a board pillar environment using trackless mechanised mining equipment for most mining activities and tasks. The hybrid mining method is a combination of the manual and mechanised methodologies (Nong 2010). It is imperative to get the proper classification framework as this might empower stakeholders to understand better what exactly is meant by mechanisation (or modernising) of hard rock mines. In an Australian environment, modernising mines will largely be understood to mean automation. Lynas and Horberry (2011) classify different levels of automation into three broad categories, namely:

- Lower level automation: This is where the human being (operator in particular) is in full control of the system and technology only assists with warnings, for instance proximity detection systems.

- Midlevel automation: This level involves having an operator control the equipment from a nearby location. The operator is in control at most times, but some functions are controlled by the system.

- Full automation: In this category, the operator is in a remote location and controls the equipment using computers, joysticks and other controls.
Based on the above classification by Lynas and Horberry (2011), one can conclude that South African mines are in different stages of automation. Moving from one level of automation to another can have a different socio-economic effect (including comprehension and understating) for different stakeholders.

\section{State of knowledge}

There is a consensus in literature that modernising (mechanising or automating) mines is driven by the desire to improve safety and productivity in mines. Lynas and Horberry (2011) identify the following drivers for mechanising mines:

- Efficiency and reliability: Machines are generally cheaper and more efficient than humans.

- Safety: There is increased responsibility on the mining leadership and stakeholders to operate safe mines and this has led to the increased drive towards mechanisation.

- Costs and productivity: Machines are generally thought to be more productive and free humans to perform other important tasks such as planning and other decisionrelated tasks.

- Increased orebody access: Mechanisation can improve the access to orebodies that were previously hazardous and unprofitable if mined through conventional means.

- Consistence and stability of operations: Machines are thought to provide process consistency and reliable data and information.

Most of the literature (Botha 2015a; Boudreau-Trudel et al. 2014; Fisher \& Schnittger 2012; Hattingh et al. 2010; Horberry, Burgess-Limerick \& Steiner 2010; Kaupp et al. 2010; McNab et al. 2013; Nong 2010; Parasuraman, Sheridan \& Wickens 1997) agree with the paraphrased summary from Lynas and Horberry (2011). There have been modernisation initiatives such as proximity detection systems that have reduced vehicle-to-vehicle (and vehicle-to-person) accidents. Some Council for Scientific and Industrial Research (CSIR) initiatives like GOAFWARN and FOGWARN have undoubtedly contributed better management of excavation stability.

In addition to the above summarised benefits of mechanisation, Hattingh et al. (2010) add another RSA specific dynamic which relates to the achievement of legislative requirements of gender transformation in the mining industry. They postulate that mechanisation results in less labour-intensive requirements from humans and, as such, women and occupationally challenged workers can still be accommodated by the industry. Other socio-economic effects that were suggested by Kaupp et al. (2010) are that skilled professionals and operators might be located in areas remote from the actual mining site. The location of some mining personnel (usually skilled and with more disposable income) would have an impact on the micro-economic development of mining communities.

There is also increased scepticism on the validity and shared vision of the above benefits of mechanisation. Regarding the 
shared vision behind mechanisation, Lynas and Horberry (2011) suggest that mechanisation is driven from four major areas, namely:

- Companies with particular interest in profitability, costs, efficiency and safety issues.

- Original equipment manufacturers (OEM) and suppliers with an interest in product differentiation to increase their market share.

- Workers with an interest in improving their specific local challenges.

- Technology researchers and developers with a particular interest in improving their specific local challenges.

Boudreau-Trudel et al. (2014) measured the impact of new equipment and innovations in 10 mining projects based in North America. The analysis of each machinery lasted over a year, and the results showed that the introduction of new equipment did not necessarily improve productivity and efficiency. In fact, in most cases the productivity was reduced. Major reasons for this rejection of the innovations by the operator were skills shortages, different machine functions and standards. Musingwini and Minnitt (2008) used analytic hierarchy process methodologies to compare different efficiencies of different mining methods in RSA platinum. Although the study was not comparing mechanisation stages or equipment, it did show that the conventional method (largely manual based) was more efficient than both the mechanised and hybrid mining methodologies. Lynas and Horberry (2011) seem to concur with these findings as they argue that humans provide flexibility and creativity to operations; machines cannot provide these. This is often underestimated by proponents of mechanisation, especially the ability by humans to adapt to unplanned scenarios and conditions. Also, in most cases, automation does not replace the human being but tends to introduce a new set of tasks and increased workloads, thus leading to distrust between the management and operators.

Some of the recorded socio-economic effects of mechanising mines are:

- Elimination of some jobs: This was recorded as early as the 1960s by authors such as Rico (1966). Although Rico (1966)'s study focused on the automation of the manufacturing sector, it suggested that the overall net effect of job losses was not significant because new jobs were created. McNab and Garcia-Vasquez (2011) estimate that about $30 \%-40 \%$ of the workforce from the mining community lost their jobs due to mechanisation of an open pit mine. However, in some open pit mines the job losses were estimated to be as high as 75\% (Bellamy \& Pravica 2010). They further posit that there would be reduced populations in mining towns as most work would be carried out remotely. The skills profile would also change as there would be a decrease in lower skilled labour and an increase in higher skilled people, but based in remotely controlled centres. The effect of job losses seems to be the major reason that some stakeholders (labour unions) are against mechanisation. A review of stakeholder opinions regarding the mines of the future in Australia by Lynas and Horberry (2011) indicates that most stakeholders were concerned with technological implications, skills implications, maintenance and organisational issues of the modernised mines. The same authors further note that there were different opinions among different stakeholders. For instance, senior mine managers were more worried about productivity benefits while end users (mostly lower level employees) were concerned about how technology would impact their job roles. Lynas and Horberry (2011) identify five factors that are critical for an effective modernisation process, namely operator acceptance, skilling, user technology interface design, human system integration and trust in technology. McNab et al. (2013) further note that most employees from local mining communities work entry level (and operator level) type of jobs with relatively less education. It is this type of workforce level that would be affected the most by the modernisation of mines. The net effect would be extended to the actual mining communities as they lose out on some businesses, such as accommodation and access to workers' disposable incomes. All these factors are human factors, but the mining industry has traditionally been perceived as not embracing a human-centred (stakeholder view) approach to modernising mines.

- Creation of new jobs and roles: Mechanisation has the potential to create jobs for people with skills in other areas. For instance, Botha (2015a) and Hattingh et al. (2010) allude to the fact that mechanising South African mines would create jobs for engineers, information technology and maintenance artisans. Dudley, McAree \& Lever (2010) estimate that 190 skilled automation support staff would be required each year to fill a total of 1500 positions in the next 15 years to sustain the implementation of automation in Australian mining. The potential for modernisation to create other forms of jobs and trades is also concurred by McNab and Garcia-Vasquez (2011) and McNab et al. (2013). However, all these examples are from a context that is slightly different from a first world country like Australia where the literacy rates are higher than South Africa, and this can have an effect on the ability to reskill operators.

\section{Global context - Key learnings and approaches}

Most of the work on the socio-economic effects of modernising the mining industry has been carried out by Australia and North America. England also used to contribute a lot in the research before the collapse of their coal mining industry. The Australians are approaching the socio-economic effects of mechanisation from an automation angle with more urgency than their RSA counterparts. For instance, they established a programme called the Mineral Futures Collaboration Cluster that brought together researchers from The University of Queensland, Curtin University of Technology, University of Technology Sydney, Australian National University, CQ University, Monash University and their CSIRO to research these challenges. 
There has not been such large-scale collaboration on this subject in the RSA mining industry. Also, the Mineral Futures Collaboration Cluster had a budget of about R100 million over 3 years; this is a large amount compared to the budget for an almost similar organisation in RSA (Centre for Mechanised Mining Systems - CMMS). CMMS had a total budget of R5 million over the last 3 years. This has an effect on the capacity and capability (internal and contracting) of institutions. For instance, the Mineral Futures Collaboration Cluster has already published almost 30 referred articles on this subject while there have been a handful of publications from the RSA side. This is paradoxical because the socio-economic effects would be felt more in the RSA than in Australia. In all these, the Australians still feel that they are not doing enough ( $\mathrm{McNab}$ et al. 2013). The current lack of research capacity in RSA is also noted by Porter (2014). In the same article, Porter (2014) highlights that most of RSA's research focus has been on the mechanistic issues that are related to modernisation, such as costs and efficiencies.

In conclusion, the socio-economic effects of mechanisation can easily result in serious socio-economic conflicts, as demonstrated by how Luddites in England attacked cities, torching factories and machinery in the early 1900s. Also, research from other industries shows that mechanisation and automation improves productivity and that job losses are at times not as dire as would have been anticipated. Other industries have shown that mechanisation and automation may (at times) come with human-related issues such as boredom, complacency and deskilling, which can reverse the potential gains of mechanisation and automation.

\section{Lessons for the South African context}

Mechanisation and automation in some South African mining sectors is already at a world class stage, such as in most coal mines. Gold and some PGMs have generally lagged behind the coal mines because of the nature of the deposits. Hard rock mines can adopt ways that coal mines have successfully used to automate. However, there does not seem to be much referred material that explicitly explains how the coal industry caters for socio-economic issues. One possible reason would be that coal mines mechanised during the apartheid era when socio-economic issues of all mine workers were not important. South African research on mechanisation has largely focused on the efficiency or productivity (including occupational health and safety) benefits (Harrison 2006; Menasce \& De Jager 2006; Nong 2010; Willis et al. 2004). An article by Willis et al. (2004) on the framework for mechanising mines explicitly states the importance of consulting different stakeholders. However, there seems to be a perception that companies who own internal change management programmes cover these socio-economic issues. Most of the referred publications on RSA's context are from the CMMS. South African mining companies are also not an exception in being slow to embrace the humancentred approach to modernisation, as is also implied by
Hattingh et al. (2010). The mining industry around the world generally neglects the socio-economic effects of some of these initiatives. The other factor that slows research in South African mining is the tripartite arrangement of managing research, that is, most research initiatives and projects must be approved by all stakeholders (companies, labour unions and government). While this works in normal engagements, it becomes a serious hindrance when it comes to research approvals and focus areas as there may be capacity and capability limitations among stakeholders. Vogt and Hattingh (2016) correctly suggest that the South African mining industry must also adopt principles of human and organisational behaviour, trial sites, simulations and promote applied research to fully benefit from mechanisation.

\section{Critique of the current thinking}

Most of the current thinking around the socio-economic effects of modernising the mining industry is informed by the Australian influence, mainly because Australia has wellfunded and dedicated initiatives such as Mineral Futures Collaboration Cluster. However, the context and conditions in Australia are different from RSA. Firstly, Australia is a developed nation while RSA is developing, with lower literacy levels. Further, most Australian mines are open pits while most RSA hard rock mines are underground mines. This presents completely different challenges especially in the size and skills of people that would be affected by mechanisation. For instance, the total workforce in the Australian mining industry can be compared to the current workforce in RSA platinum mines only. Thus, the socioeconomic effects would be more dire in RSA than in Australia and any conversation on the subject tends to be emotional and political in RSA. Also, because of the stage of automation in Australian mines, the discussions are more focused on the ergonomic effects of mechanisation as opposed to RSA where the discussion is still at a conceptual stage.

Literature also fails to acknowledge that mining is a primary industry and, as such, there are some forms of emotions that seem to be attached to these types of industries. All over the world mining invokes the same emotions that are invoked when discussing land (farming) or forestry. It would greatly assist the understanding of this subject if these socioeconomic effects are not viewed with the same lens as those used to view socio-economic effects of automating a pilot cabin or banks. Lastly, most literature focuses more towards mine workers and tends to neglect mining communities. As such, not much in-depth study has been carried out on communities surrounding mines. RSA also brings in another dimension in this category in the form of remote labour-sending communities. These specific areas, villages, provinces and tribes are historically known to groom and send their people to work in mines. In developed countries like Australia, labour-sending areas are normally big, wellestablished cities that do not explicitly depend on these migrant workers. In RSA, some of these villages largely depend on these migrant workers. Most workers from these labour-sending areas perform manual labour and are likely 
to be affected by mechanisation; therefore, the net effect of mechanisation would also be felt in these areas.

\section{Research approach, sample selection and data collection}

The specific data collection methodology chosen for this research was semi-structured individual interviews. The interviews were mainly face-to-face but there were some that were carried out remotely. A total of 21 stakeholders were interviewed, ranging from operators, executives, academics, union leaders and consultants. Most of the sampled population were operators, and the sample distribution in the sampled population was fairly representative of the RSA hard rock mines. The overall qualifying criteria for this sample selection included anyone working in RSA hard rock mines, any stakeholder who is affected by mechanising of hard rock mines and with knowledge of, or experience in, the socioeconomic effects of mechanisation.

Furthermore, some union leadership representatives who participated in the study provided their official organisational position on the questions asked and, as such, they were comfortable with their views being provided to the public. The primary method of data collection was in the form of open-ended, one-on-one, semi-structured interviews. Interviews with most operators and supervisors were conducted in underground working spaces because most operators work there and do not have time on surface.

\section{Analysis of findings Understanding of mechanisation and modernisation}

Participants were asked to describe what they understood about mechanisation and modernisation. Seventeen (17) of the 21 interviewees (81\%) had a basic understanding of the subject, while the other 4 participants $(19 \%)$ had no knowledge of the subject and the interviewer had to explain to them. The different levels of understanding are illustrated in Table 1 below.

There seems to be a direct relationship between the understanding of mechanisation and levels of education. Most participants in the sampled population had a basic understanding of mechanisation. Participants who had no prior knowledge of mechanisation were operators with no formal education qualifications. Senior principals from both employer and employee representatives showed extensive

TABLE 1: Levels of understanding mechanisation and modernisation.

\begin{tabular}{llll}
\hline $\begin{array}{l}\text { Level 1: No } \\
\text { understanding }\end{array}$ & $\begin{array}{l}\text { Level 2: Basic } \\
\text { understanding }\end{array}$ & $\begin{array}{l}\text { Level 3: Good } \\
\text { understanding }\end{array}$ & $\begin{array}{l}\text { Level 4: Extensive } \\
\text { understanding }\end{array}$ \\
\hline $\begin{array}{l}\text { No prior knowledge } \\
\text { (interviewer had to } \\
\text { explain) }\end{array}$ & $\begin{array}{l}\text { Understand it as } \\
\text { the substitution of } \\
\text { labour with } \\
\text { machines }\end{array}$ & $\begin{array}{l}\text { Demonstrate basic } \\
\text { understanding }\end{array}$ & $\begin{array}{l}\text { Demonstrate good } \\
\text { understanding }\end{array}$ \\
& $\begin{array}{l}\text { Understand it to } \\
\text { form part of } \\
\text { human transition } \\
\text { or development }\end{array}$ & $\begin{array}{l}\text { Elaborated } \\
\text { benefits and } \\
\text { disadvantages }\end{array}$ & $\begin{array}{l}\text { Can differentiate } \\
\text { between } \\
\text { mechanisation and } \\
\text { modernisation }\end{array}$ \\
\hline
\end{tabular}

knowledge of mechanisation and modernisation and all perceived it as an opportunity to improve value for all stakeholders.

\section{Views mechanisation and/or modernisation}

Based on their understanding of mechanisation, participants were asked to explain their views on mechanisation and modernisation. All participants unanimously supported and easily identified the benefit of mechanisation. This includes the participants ( $19 \%$ of the population) who previously did not have a prior understanding of mechanisation. Participants' answers had common themes, but the foci differed depending on the level of understanding of the subject. Common themes for level 1, level 2 and level 3 are that mechanisation or modernisation would:

- improve occupational health and safety

- improve production and productivity

- reduce the need for manual labour.

One view that was exclusively from a level 3 category was that mechanisation should follow an extensive change management process and more people should be educated on the initiative.

Level 4 themes were related to level 1, level 2 and level 3 themes but with a broader focus. Some of the themes identified are:

- Achieve the zero harm vision (every employee should return home unharmed every day): This relates to the common theme of improving occupational health and safety identified by level 1, level 2 and level 3. All participants in this category acknowledged that RSA mines are becoming too deep and dangerous to mine safely using the current methods; thus, sending machines and automating would make them safer and reduce mining-related fatalities.

- Improve life of mine: This theme was also unanimous among level 4 participants. The participants were unambiguous in explaining that the vast mineral reserves are at depths that are expensive to mine using the current methods but may be feasible when mined by machines.

- Improve the industry's competitiveness and attraction of investors: This theme was common for all labour unions. The participants acknowledged that current mining industry challenges of labour unrest, high costs and productivity issues are not attractive to investors. On further probing, they acknowledged that the challenges are not personality based but more on the need for the mining industry to holistically reinvent itself and be attractive to all stakeholders (investors, workers and communities).

- Leverage on new technologies and invention: This was articulated by mining professionals in level 4 category, including the professor from CMMS. On probing the basis of this point, participants were concerned that the industry is slow in leveraging on the current innovations and improvements in technology when compared to other industries. 
- One mining professional identified mechanisation as a critical strategy to save cost and cushion the mines from commodity price fluctuations.

- Save jobs in the long term: Due to the expected increased life of a mine. Their rationale here was that if mining continued in its current form, it would soon be unsustainable, and most deposits would not be mineable. As such, most people would lose their jobs. However, if they mechanised now, fewer people would lose their jobs in the short term but more would gain in the long term. Both employers and employees in the level 4 category agreed on this. However, one union (Solidarity) emphasised that the mining industry had to try by all means to retain as many jobs as possible and at all levels. They further wanted equitable beneficiation of retrenched workers and communities, including the upskilling and reskilling of retrenched workers so that they could participate in other downstream and upstream mining processes.

\section{Stakeholders affected by mechanisation and modernisation}

Participants were asked to identify potential stakeholders who were likely to be affected by mechanisation; this was normally followed by the probing question of how these stakeholders would be affected. This question was at times reposed at the end of some interviews because some participants (level 1 and level 2) initially gave too broad answers such as 'everyone'. The following stakeholders were identified by the participants as the potential people to be affected by mechanisation:

- Employees: $50 \%$ of the participants were of the view that mechanisation would lead to job losses because machines would substitute manual labour. Most participants (82\%) who identified this effect were of the level 1 and level 2 participants while the other $18 \%$ were employee representatives classified as level 4 participants. Furthermore, $18 \%$ of the sampled population were explicit that job losses would mostly affect the old and less educated employees. This sample population represents about $36 \%$ of participants who had initially identified the negative ramification and all of them were level 1 and level 2 participants.

- Mine owners, shareholders and management: About $24 \%$ of the participants identified mine owners and management as being critical stakeholders of mechanisation. These were mostly level 3 and level 4 participants but there was one supervisor (from level 2) who concurred with them. The main cause of this was the huge capital requirements needed for mechanisation and modernisation; thus, the short-term effects would be negative but with positive long-term effects.

- Mining communities (including labour-sending areas): This was identified by $19 \%$ of the sampled population, all of which were level 4 participants. Stakeholders in this category (representing about $68 \%$ of level 4 participants) clearly viewed communities as people who would be affected both positively and negatively by modernisation. The positive impact would be from improved reduction in mining-related environmental hazards due to safe mining methods (precision) from machinery. The other positive effect would be improved income from increased life of mines and increased profitability. These benefits would be limited to communities around the mining operations. Laboursending communities would be affected negatively as there would be loss of income; this might come with negative social ills such as crime or political instability. The profile of the migrant worker would also change as they would likely be specialists and from major cities and not from the current remote areas.

- Labour unions and worker profile: This was also raised by $19 \%$ of the participants, all of whom were level 4 participants. The main issue here is that mechanisation would largely change worker profile and demographics as there would be more skilled and educated workers. This would also change the nature and level of engagements between workers and employers. Issues such as the long drawn-out and violent strikes of 2013/2014 might no longer happen due to the long-term focus of discussions among stakeholders and less diversity of socio-economic needs among workers.

- Original equipment manufacturers (OEM) and suppliers: This was raised by level 4 participants from different constituencies. It is envisaged that the current OEMs and suppliers would have to reinvent themselves and supply equipment that would be required by the mines of the future. There would also be opportunities for new entrants.

- Training institutions: The emphasis is that training institutions might have to relook at their offering and adjust to the needs of a mechanised industry.

\section{How mechanisation and modernisation individually affects participants}

Participants were then asked to describe how mechanisation and modernisation individually affected them. The identified effects on an individual level are summarised in Table 2. In Table 2, the opportunity column refers to participants who saw personal opportunities in this initiative, while the calamity column refers to participants who foresee serious personal challenges with this mechanisation initiative. Of the participants, 38\% were scared that machines would substitute them, thus leading to loss of their jobs. These participants were all level 1 and level 2 participants (about 53\% of this category). A significant number of level 1 and level 2 participants (33\% of this category and $24 \%$ of the population) also saw potential

TABLE 2: Effects of mechanisation and modernisation at an individual level. Opportunity: Participants see personal Calamity: Participants see opportunities personal challenges

- Continuous reskilling - Job losses

- Increase in union membership numbers

- Focused engagements among stakeholders

- Learn new mining methods

- Implement business process changes (and

improve production)

- Change of profession 
opportunities in mechanisation. These opportunities include reskilling, learning new mining methods and changes in profession. Of level 3 and level 4 participants, $83 \%$ saw the opportunity in having focused engagements with labour due to the reduced diversity of socio-economic needs among stakeholders. Mining executives $(10 \%$ of the population) saw a potential opportunity to implement business process changes and productivity improvement initiatives that would make shafts sustainable. The two level 2 participants aged above 50 years $(10 \%$ of the population) were confident that mechanisation would not personally affect them as they would have retired by the time it was implemented.

As part of probing, some interviewees were also asked to estimate the times they were likely to feel the effects of modernisation and estimates varied from now to 10 years' time. Further, a total of five level 4 participants (83\% of this category) were asked whether the stakeholders were doing enough to prepare for the new world. Everyone was unanimous on the fact that stakeholders were not doing enough even though some engagements had begun as part of government's Mining Phakisa project and CCMI initiatives. However, most critical stakeholders such as labour had limited knowledge and participation in these initiatives.

\section{Ethical consideration}

The project has been subject to ethical review in accordance with the procedures specified by the University of Reading Research Ethics Committee and has been given a favourable ethical opinion for conduct.

\section{Discussion of results}

One of the major findings of this research is that stakeholders have different levels of understanding of mechanisation and modernisation. The levels of understanding were found to be proportional to the levels of education and not related to classifications such as gender, race, commodity mined and type of jobs. It seems that the different levels of understanding of mechanisation and modernisation have a limited influence on how participants viewed the impact of socio-economic effects because the effects identified by different participants at different levels were largely related. Most participants in the sampled population had a basic understanding of mechanisation and modernisation. Reviewed literature seems to indicate that researchers do not initially establish the participants' levels of understanding of this subject and generally move straight ahead to explore the views of stakeholders. This is probably so because most of the literature on this subject is from developed countries such as Australia who have high literacy rates. Nevertheless, this initial probe was invaluable in this instance as it demonstrated that stakeholders' perception of socio-economic challenges is not limited to their constituency or needs but more to their comprehension of the challenge. For instance, there are a couple of examples in the previous section where labour unions raised issues that were of interest to shareholders, investors, country competitiveness and communities and level 1 and level 2 participants (workers) who raised concerns of capital requirements that accompany mechanisation.

There seems to be general support for mechanisation and modernisation among the participants. The identified benefits and challenges were relatively similar and aligned among participants. The main difference, however, was in the depth and scope of the problem or opportunity as perceived by participants. For instance, while mining executives mentioned issues like achieving the zero harm vision, lower level employees would mention safe working place. The more educated participants naturally had a more holistic view of the socio-economic effects and could logically relate them to causes when probed, while the less educated participants struggled with this. Literature by Lynas and Horberry (2011) suggests that different stakeholders have different opinions on the socio-economic effects of mechanisation and studies acknowledge this observation. However, this research has shown that this difference in opinions is probably driven more by different levels of understanding as opposed to different interests.

Participants expect mechanisation and modernisation to affect the following stakeholders:

- Employees (i.e. job losses) - This was identified by most participants and is in line with observations in literature by authors such as Bellamy and Pravica (2010) and McNab and Garcia-Vasquez (2011). The participants are justified to be wary of this factor because literature has cases where the job losses were as high as $40 \%$ (and 75\% at some sites). However, literature also acknowledges that job losses might not be that big because there would be employment opportunities in upstream processes, as demonstrated by authors such as Botha (2015a), Hattingh et al. (2010) and Dudley et al. (2010). Job losses are likely to be felt by lower level employees currently doing operator type of jobs; this would be more severe for older employees (above 45 years).

- Mining owners and shareholders - Mechanisation and modernisation as a capital-intensive initiative would likely cause short-term losses for the companies, albeit with longer-term benefits. It is generally not explicitly clear whether this would be an industry initiative in RSA, because if companies could leverage on the economies of scale then envisaged losses would be minimum.

- Mining communities (operations) - None of the participants was a mining community representative; nonetheless, they were identified as critical stakeholders who would be affected by modernisation of mines. There would likely be long-term benefits for the communities where the actual mining operations are located due to perceived improvement on mine profitability and the life of mines, which would in turn increase the local royalties. 
- Mining communities (labour-sending areas) - There would be a loss of income in the current labour-sending areas. Literature does not seem to focus much on this fact because in developed countries, labour-sending areas are normally big cities and communities are not directly dependent on migrant labour. However, in RSA some of these villages depend heavily on the income from these migrant workers. Workers that are likely to lose their jobs are from these labour-sending areas. It is also worth noting that in mines that are close to full automation, the origins of labour-sending areas tend to be cities as opposed to remote areas. This fact was also observed in literature by Kaupp et al. (2010).

- Labour union and employee profile - In line with what McNab and Garcia-Vasquez (2011) and McNab et al. (2013) suggested, participants foresaw a change in the employee profile due to mechanisation. The interviewees foresaw a more literate employee, which might reduce diversity of socio-economic needs among stakeholders. This would in turn make stakeholder engagements more focused. This came out strongly and seems to frustrate participating unions, senior management and mining professionals.

- Other stakeholders (Department of Mineral Resources, OEMs, suppliers and training institutions) - Even though these stakeholders were not represented in the study, different participants at different levels identified mechanisation as having an impact on them and the way they offer and deliver services to the industry.

Interviewees were also unanimous in identifying the social-economic benefits of mechanisation. The identified benefits included occupational health and safety issues, efficiency, costs and improved life of mines. All these are in line with the benefits identified in literature by BoudreauTrudel et al. (2014), Botha (2015a), Fisher \& Schnittger (2012), Hattingh et al. (2010), Horberry et al. (2010), Kaupp et al. (2010), Lynas and Horberry (2011), McNab et al. 2013; Nong 2010; Parasuraman et al. 1997).

On a personal level, most participants (irrespective of education levels) viewed mechanisation and modernisation as an opportunity to reskill themselves, improve operations and improve quality of life. The potential job losses seemed to be secondary when asked at a personal level. This was also contrary to common perception and was probably influenced by an increase in access to information and technology, which might be making people accept technological changes as part of life.

Overall, participants (irrespective of their educational levels) seemed mature enough to look beyond their constituencies and interests when exploring the socioeconomic impacts of mechanisation and modernisation. The only notable hindrance was the level of education, which in turn influenced the depth and comprehension of issues, but this did not influence the principles.

\section{Results limitations}

Some of the limitations of this study are:

- Not all labour union principals were represented The two unions' leadership whose members are most likely to be affected by job losses were not represented in the study despite repeated efforts to engage them. One of these unions blatantly refused (in writing) to participate in the study. The other had capacity issues and was always busy with other challenges such as wage negotiations. However, it is important to mention that most of the interviewees (over 60\%) were from these two unions so some of their members were represented.

- No representation from communities - The interviews did not manage to obtain the views of communities because it was difficult to find legitimate representatives within the limits of the planned timelines.

- Need for quantitative research - Most of the issues identified by stakeholders and literature are backed with adequate quantitative numbers. For instance, one is not sure of the approximate number of people likely to lose jobs, and if (for instance) the industry fully mechanises in 10 years' time, workers who are above 50 years old may not be involved in the analysis and scenario planning exercise.

- This research was cross-sectional and collected data during the wage negotiation year; it would add more value if a more detailed research were carried out in a longitudinal manner.

\section{Conclusions}

The following conclusions can be drawn from the study results:

- Stakeholders seem to be able to see beyond their interests for the benefit of the mining industry. Also, the stakeholders' interests are reasonably aligned and largely common.

- Stakeholders do support mechanisation and modernisation efforts. However, the leadership of different stakeholders must engage with one another and with their members to measure and categorise different stakeholder needs and apply them as part of the implementation plan for mechanisation and modernisation.

- Mechanisation and modernisation efforts require a multistakeholder approach that should be accompanied by thorough research to scientifically quantify the probable effects on stakeholders.

- Mechanisation and modernisation should follow both quantitative and qualitative research methodologies.

- There is room for other stakeholders, especially government institutions like the Department of Mineral Resources and the Mine Health and Safety Council to take a more visible role in this initiative.

- There are apparently few published, documented and referred articles on the socio-economic impact of 
modernising RSA mines. The results presented in this article are believed to be the first such data and will contribute to the discussion.

\section{Recommendations}

The following recommendations can be drawn from this research:

- There is need for a comprehensive approach to the socioeconomic impact of mechanisation on the South African mining sector; that way, mines may gain more by being uniformly integrated and aligned in a manner that would reflect the industry's initiative as opposed to it appearing as an individual company's initiative. Further, such a move would allow for easy sharing of resources and experience.

- In seeking to mitigate the socio-economic impact of mechanisation, companies need to gradually incorporate these changes into their change management programmes.

- There is still need for much more in-depth research (both qualitative and quantitative) on the socio-economic impact of mechanisation on the mining industry, with specific focus on the variegated communities - both labour-sending communities and those in close proximity to the location of the different mining companies.

- There is a need for the government to work in consultation with other stakeholders in establishing a permanent unit which would be responsible for coordinating this industry initiative and providing some form of project management office services. This is necessitated by the clear lack of ownership of such a policy initiative by both captains of industry and government.

\section{Managerial contributions}

This is probably the first research of this kind on the subject in RSA and in the hard rock mining environment. The research will contribute to the elimination of the current perception that operators and ordinary workers are opposed to and do not comprehend the value of mechanising and automating the RSA hard rock mines. Lastly, this report further emphasises the importance of extensive stakeholder consultation when carrying out these types of initiatives.

\section{Theoretical contributions}

This research has provided a base framework for classifying different levels of the understanding of mechanisation and automation in RSA mining. These different levels will need different interventions when conducting change management initiatives.

\section{Acknowledgements}

The research described in this article was carried out by the author for a dissertation at University of Reading (and Henley Business School). The research and studies were funded through Oceana Business Re-Engineering, Ayanda Mbanga Communications and Letaba Elihle Investments. The assistance by all interviewees is appreciated.

\section{Competing interests}

The authors declare that they have no financial or personal relationship(s) that may have inappropriately influenced them in writing this article.

\section{References}

Bellamy, D. \& Pravica, L., 2010, 'Assessing the impact of driverless haul trucks in Australian surface mining', Resources Policy 36(2), 149-158. https://doi.org/ 10.1016/j.resourpol.2010.09.002

Botha, D., 2015a, Global trends and development in mechanisation and automation with specific reference to HSEC and social dimensions, internal NOSA report, Chamber of Mines South Africa, Johannesburg.

Boudreau-Trudel, B., Zaras, S., Nadeau, S. \& Deschamps, I., 2014, 'Introduction of innovative equipment in mining: Impact on productivity', American Journal of Industrial and Business Management 4(1), 31-39. https://doi.org/10.4236/ ajibm.2014.41006

Chamber of Mines of South Africa, 2009, South African Yearbook 2008/2009, Chamber of Mines, Johannesburg.

Chamber of Mines of South Africa, 2014, South African Yearbook 2013/2014, Chamber of Mines, Johannesburg.

Department of Minerals and Energy, 2009, Directorate of minerals economics, Annual report, 2009/2010, Department of Minerals and Energy, Pretoria.

Dudley, J., McAree, R., \& Lever, P. 2010, 'Automation for success', technical report from Mining Industry Skill Centre, Brisbane, Australia.

Egerton, F.M.G., 2004, 'Presidential address: The mechanization of UG2 mining in the Bushveld Complex', Journal of the South African Institute of Mining and Metallurgy 104(8), 439-455.

Fisher B.S. \& Schnittger, S., 2012, 'Autonomous and Remote operation technologies in the mining industry benefits and costs', BAE Research Report 12.1, BAE, Canberra

Harrison, G.A., 2006, 'Implementation of extra low profile (XLP) mechanized equipment in Anglo Platinum', Journal of the South African Institute of Mining and Metallurgy 106(8), 527-532.

Hattingh, T.S., Sheer, T.J. \& Du Plessis, A.G., 2010, 'Human factors in mine mechanisation', in The 4th International Platinum Conference, Platinum in transition 'Boom or Burst', The Southern African Institute of Mining and transition 'Boom or Burst',
Metallurgy, Johannesburg.

Horberry, T., Burgess-Limerick, R. \& Steiner, L.J., 2010, Human factors for the design, operation, and maintenance of mining equipment, CRC Press, Boca Raton, FL.

Horberry, T., Larsson, T., Johnson, I. \& Lambert J., 2004, 'Forklift safety, traffic engineering and intelligent transport systems: A case study', Applied Ergonomics 35(6), 575-581. https://doi.org/10.1016/j.apergo.2004.05.004

James, N., 2016, Mechanisation plans should consider socioeconomic impact. Creamer Media's Mining Weekly, viewed 15 May 2016, from http://www.miningweekly. $\mathrm{com} /$ print-version/mechanisation-plans-should-consider-socioeconomicimpact,1-5

Kaupp, T., Makarenko, A. \& Durrant-Whyte, H., 2010, 'Human-robot communication for collaborative decision making: A probabilistic approach', Robot Autonomous Systems 5(58), 444-456. https://doi.org/10.1016/j.robot.2010.02.003

Lynas, D. \& Horberry, T., 2011, 'Human factor issues with automated mining equipment', Ergonomics Open Journal 4(1), 74-80. https://doi.org/10.2174/ 1875934301104010074

McNab, K.L. \& Garcia-Vasquez, M., 2011, 'Autonomous and remote operation technologies in Australian mining', prepared for CSIRO Minerals Down Under Flagship, Minerals Futures Cluster Collaboration, by the Centre for Social Responsibility in Mining, Sustainable Minerals Institute, The University of Queensland, Brisbane.

McNab, K.L., Onate, B., Brereton, D., Horberry, T., Lynas, D. \& Franks, D.M., 2013, 'Exploring the social dimensions of autonomous and remote operation mining: Applying social license in design', prepared for CSIRO Minerals Down Under Flagship, Mineral Futures Collaboration Cluster, by the Centre for Social Responsibility in Mining and the Minerals Industry Safety and Health Centre, Sustainable Minerals Institute, The University of Queensland, Brisbane.

Menasce, J.R. \& De Jager, J.B., 2006, 'A review of mechanized versus handheld bolting in hard rock tabular orebodies', Journal of the South African Institute of Mining and Metallurgy 106(5), 545-552.

Mining Qualifications Authority (MQA), 2014, MQA Workplace Skills Plan and Annual Training, reports analysis of grant applications submitted to the MQA, MQA, Johannesburg. 
Musingwini, C. \& Minnitt, R.C.A., 2008, 'Ranking the efficiency of selected platinum mining methods using the analytic hierarchy process (AHP)', in Third International
Platinum Conference 'Platinum in Transformation', pp. 319-326, The South African Institute of Mining and Metallurgy, Johannesburg.

Nong, S., 2010, 'Review of successes and failures of mechanisation trials on platinum mines of the Bushveld Complex', MSc Eng. dissertation, University of the Witwatersrand, Johannesburg.

Parasuraman, R., Sheridan, B. \& Wickens, C., 1997, 'A model for types and levels of human interaction with automation', IEEE Transactions on Systems, Man and Cybernetics 30(3), 286-297. https://doi.org/10.1109/3468.844354

Porter, J.L., 2014, 'Are efforts to mechanize SA mines too focused on machinery rather than technology?', Journal of the South African Institute of Mining and Metallurgy 114(9), 681-692.
Rico, L., 1966, 'Automation and manufacturing employment: A reappraisal', Human Resource Management Journal 5(1), 1-10. https://doi.org/10.1002/ hrm.3930050102

Vogt, D. \& Hattingh, T., 2016, 'The importance of people in the process of converting a narrow tabular hard-rock mine to mechanization', Journal of the South African Institute of Mining and Metallurgy 116(3), 265-274. https://doi.org/10.17159/ 2411-9717/2016/v116n3a8

Willis, R.P.H., Dixon, J.R., Cox, J.A. \& Pooley, A.D. 2004, 'A framework for the introduction of mechanized mining', International Platinum Conference on 'Platinum Adding Value', The South African Institute of Mining and Metallurgy, Johannesburg, viewed n.d., from http://www.saimm.co.za/Conferences/ Pt2004/117_Willis.pdf 


\section{Appendix 1}

\section{Questionnaire and information sheet and consent form for face-to- face interviews}

Title of research project: The socio-economic effects of mechanising and/or modernising hard rock mines in South Africa

The research forms part of my academic qualification at Henley Business School at the University of Reading.

Part of the research involves interviewing people who are involved in, affected by and have knowledge/experience regarding the socio-economic effects of modernising the hard rock mines in South Africa. For this reason, I would like to invite you to take part. If you agree, you will be asked to participate in a telephone/video interview of about $60 \mathrm{~min}$

During the interview I will ask you questions such as:

- What do you understand about modernisation?

- What is your view on modernisation?
- Who will be affected by modernisation?

- How will modernisation personally affect you?

- How will modernisation affect other stakeholders?

Your participation is entirely voluntary. You can choose not to answer any particular questions and you are free to withdraw from the study at any time.

With your permission, I would like to record the interview/take notes for later analysis. The data will be kept securely and destroyed after the completion of the project.

Your identity will remain confidential throughout all stages of the research. Your name and identifying information will not be included in the final report.

The identity of your organisation will not be included in the final report. A copy of the completed project/summary of the project/ summary of findings will be available on request. The project has been subject to ethical review in accordance with the procedures specified by the University of Reading Research Ethics Committee and has been given a favourable ethical opinion for conduct. 